\title{
Consumer Decision-Making Style: The Case of Iranian Young Consumers
}

\author{
Shahriar Azizi (Corresponding author) \\ Department of Business administration \\ Faculty of Management and Accounting, ShahidBeheshti University \\ Evin, Tehran, Iran
}

Tel: 98-21-2990-2383E-mail: s-azizi@sbu.ac.ir

Vahid Makkizadeh

Department of Business administration

Faculty of Management and Accounting, ShahidBehehsti University

Evin, Tehran, Iran

Received: January 2, 2012 Accepted: February 10, 2012 Published: April 1, 2012

doi:10.5296/jmr.v4i2.1222ＵRL: http://dx.doi.org/10.5296/jmr.v4i2.1222

\begin{abstract}
Separating markets precisely and applying marketing programs proportional to the known sections is one of the most important success tools in competitive markets. Having 24 million young people aged 15-29 (32\% of total population), Iran has a young demographic structure. Concerning this demographic structure, exact recognition of CDMS of Iranian young consumers is of great importance for salespeople. Thus, this research seeks to study decision-making styles among students of shahidbeheshti university of Tehran. To validate fundamental features of these styles among Iranian young people, the CSI Model presented by Sproles and Kendal (1986) was examined. Results of the analysis show that there are only two main styles of the mentioned model (Brand Loyalty and Brand Conscious) among Iranian young consumers. Also, analyses revealed the existence of a 12-item model for decision-making style among young people of Iran: Brand Consciousness, Behavioral Perfectionist, Economic, Brand Loyal, Fashion Conscious, Confused, Economic-Hedonism, Attitudinal Perfectionist, Time-Energy Conserving, and Hate from Shopping, Variety Seeking and Undemanding. Further analysis showed that men and women are different only
\end{abstract}




\section{Macrothink}

Journal of Management Research ISSN 1941-899X 2012, Vol. 4, No. 2

in Fashion Conscious. Finally, this research has studied the effects of age, marital status and income level on decision-making style of young people of Iran.

Keywords: Consumer style inventory, Consumer decision making style, Iran 


\section{Introduction}

Consumer decision-making style (CDMS) is a hot topic in marketing literature. A marketer needs to be aware of these styles for market segmentation and designing marketing programs and strategies.One of the most attractive parts of a market for salespeople is young consumers. Since purchase decision-making style of this group has its special features, recognizing and analyzing their decision-making styles carefully and exactly can play an important role in designing and executing appropriate marketing programs. Since young people aged 15 to 29 constitute 32\% of Iran's population (24 million), recognizing their decision-making styles is of great importance for Iranian salespeople.

Consumers' shopping activities and their attitudes about shopping are believed to be direct outgrowths of their consumer decision-making styles (Tia, 2005). Consumer decision-making styles are relative stable constructs (Walsh et al. 2001) and are thought to comprise a basic part of personality Sproles and Kendal (1986). These studied styles can be viewed as "basic buying-decision-making attitudes that consumers adhere to, even when they are applied to different goods, service or purchasing decisions" (Walsh et al. 2001). Knowledge of consumer decision-making styles is clearly important to marketers and inextricably linked to purchase behavior. Characterizing shoppers in this way allows marketers differentiate their offerings both at the store and product level. This concern is particularly relevant to the debate around the standardization of multi-country marketing activities where local market conditions may require tailored marketing programmers. In addition, from a consumer affairs viewpoint, identification of the basic characteristics of decision-making styles could help to profile individuals, to educate them about their decision-making characteristics and offer financial counseling. The present study objectives are:

\section{1- Recognizing decision-making styles of young Iranian consumers}

2- Studying the effect of demographic variables on decision-making styles of young Iranian consumers

\section{The Literature Review}

Main Field of consumer behavior is seeking to identify the underlying decision styles of shoppers. A review of previous research has shown a large number of studies which have examined other aspects of the consumer's decision making behavior (See for example: Darden and Reynolds, 1971; Thorelli, Becker and Engeldow, 1975; Furse, Punj and Stewart, 1984; Westbrook and Black, 1985; Sproles, 1985; Sproles and Kendall, 1986; Hafstrom et al. 1992; Durvasala, Lysonski and Andrews, 1993; Lysonski et al. 1996; Fan and Xiao, 1998; Mitchell and Bates, 1998; Walsh, Mitchell and Thurau, 2001).

According to Sproles and Kendall (1986), the consumer literature suggests three ways to characterize consumer decision-making styles, namely, psychographic/lifestyle approach, the consumer typology approach and the consumer characteristics approach. Lysonksi et al. (1996) pointed out that among these three approaches, the consumer characteristics approach is the most powerful and explanatory one because it focused on the mental orientation of 
consumers in making decisions. Thus, decision-making styles can be determined by identifying the consumer's general orientations towards shopping and buying. Sproles and Kendall (1986) developed the Consumer Style Inventory (CSI) to measure consumer decision-making styles. In this regard, numerous studies have been carried out which have included some aspect of the consumer decision-making styles concept (Darden and Reynolds, 1971; Thorelli et al. 1975; Vestbrook and Black, 1985; Darden and Ashton, 1974; Korgaonkar, 1981; Darian, 1967; Sproles, 1985; Sproles and Kendall, 1986; MacDonald, 1993).

Moving from the general to the specific, these studies can be categorized as shopping orientation, store patronage, consumer decision-making styles and information search behavior. There is some similarity in the scale content of questionnaires used to measure these four separate areas of consumer decision-making which results in confusion and overlap between shopping orientations and decision-making styles. Moreover, many studies have used to benefit consumer seek, rather than the way in which they make decisions.

The development of many different scales has resulted in numerous typologies which serve to confuse rather than to enhance understanding. However, despite many researches, there is no single accepted decision-making typology to date. Indeed, it has been noted that generalizations about shopper types be improved by further investigation of existing scales rather than developing new ones (Durvasula et al., 1993).

Replications and extensions help guard against the perpetuation of erroneous and questionable reseals, as well as assessing the generalisability of findings from marketing studies. Furthermore, critical reviews of the marketing literature have agreed that greater attention is needed to focus on theory-driven research that systematically pursues a given subject area (Anderson, 1983; Jacoby\&Chestnut, 1978).

Academic researchers have also suggested that investigations of the generalisability of psychographic-type segments might be helpful in the development and evaluation of theory (Wind, 1978). The Consumer Styles Inventory (CSI) provides a good basis for further competitive work, since a robust questionnaire and prior research are served to compare the results (Hafstrom et al. 1992; Dun-asula et al. 1993; Lysonski et al. 1996). This reduces conceptual and measurement differences and enhances the possibility of identifying cultural differences.

Most of the general consumer decision-making studies noted in the initial paragraph have used restricted US samples and/or highly-specific product purchases which has resulted in little consistency between typologies. This is likely to be because both sample and purchase context may alter the typologies obtained. This raises the question of how useful they are to non-US. and in particular Iran, retailers, marketers and researchers. Cross-validation studies respond to the criticism that the models and empirical findings of US studies have serious validity problems in other countries (Albaum and Peterson, 1984; Lee and Green, 1991). In fact, Sproles and Kendall (1986) themselves recommended that the CSI should be administered in other populations. 
Referring to the question of generalize ability, (Hafstrom et al. 1992) examined decision-making styles of Korean students. (Dunvasula et al. 1993) used a New Zealand sample and Lysonski et al. (1996) used student samples from New Zealand, Greece, US and India. Although Korean students' styles were similar to those for US students, there were some differences. For example, the 'novelty-fashion conscious' factor was not confirmed, possibly because of the lower sophistication of Korean consumers and less developed nature of the economy (Tables 1 and 2). In addition, on close examination, there are many individual item-loading anomalies between the two studies with several items loading on more than one factor and some items not corresponding to the suggested trait.

Overall, the item loadings suggest that several factors should be renamed to reflect more accurately the items loading onto them. The authors appear to have disregarded the nature of the items in order to agree with Sproles and Kendall's (1986) findings, New Zealand students demonstrated the same original eight factors (Table 1).

Table 1. Consumer Decision-making Traits Identified in the Literature

\begin{tabular}{|c|c|c|c|c|}
\hline Sproles (1985) & $\begin{array}{l}\text { Sproles and Kendall } \\
\text { (1986) }\end{array}$ & $\begin{array}{l}\text { HafstromChae\& } \\
\text { Chung (1992) }\end{array}$ & $\begin{array}{l}\text { DLyuorvnasskui } \\
\text { and } \\
\text { Andrews (1993) }\end{array}$ & $\begin{array}{l}\text { DLuyrvoanssuhklai, } \\
\text { and } \\
\text { Zotos(1996) }\end{array}$ \\
\hline \multirow{3}{*}{$\begin{array}{l}\text { Perfectionistic } \\
\text { Value } \\
\text { Consciousness }\end{array}$} & Perfectionistic & Perfectionistic & Perfectionistic & Perfectionistic \\
\hline & Price-Value & Price-Value & Price-Value & Brand \\
\hline & Consciousness & Consciousness & Consciousness & Consciousness \\
\hline Brand & Brand & Brand & Brand & novelty-Fashion \\
\hline Consciousness & Consciousness & Consciousness & Consciousness & Consciousness \\
\hline novelty-Fashion & novelty-Fashion & Confused by & novelty-Fashion & Confused by \\
\hline Consciousness & Consciousness & Over choice & Consciousness & Over choice \\
\hline Shopping & Confused by & Recreational & Confused by & Recreational \\
\hline Avoiding & Over choice & Consciousness & Over choice & Consciousness \\
\hline \multirow{6}{*}{$\begin{array}{l}\text { Confused by } \\
\text { Over choice }\end{array}$} & Recreational & & Recreational & \\
\hline & Shopping & Impulsiveness & Shopping & Impulsiveness \\
\hline & Consciousness & & Consciousness & \\
\hline & Impulsiveness & $\begin{array}{l}\text { Habitual, Brand } \\
\text { loyalty }\end{array}$ & Impulsiveness & $\begin{array}{l}\text { Habitual, Brand } \\
\text { Loyalty }\end{array}$ \\
\hline & Habitual, Brand & Time-Energy & Habitual, Brand & \\
\hline & loyalty & Conservation & loyalty & \\
\hline
\end{tabular}




\section{The Consumer Styles Inventory and Consumer Decision-Making}

Based on empirical research, Sproles and Kendall (1986) designed the Consumer Styles Inventory to determine consumers' styles of decision-making in the marketplace.

The CSI has pointed towards a new direction in the consumer decision-making research. The CSI provides a good base for additional comparative work as it is a robust questionnaire and it can be used to compare the results with prior research (Sproles and Kendall, 1986; Hafstrom et al., 1992; Durvasala et al., 1993; Lysonski et al., 1996; Fan and Xiao, 1998; Mitchell and Bates, 1998; Walsh et al., 2001).

In turn, this will aid in the reduction of conceptual and measurement differences and will further augment the possibility of identifying cultural differences. With prior research (Sproles and Kendall, 1986; Hafstrom et al., 1992; Durvasala et al., 1993; Lysonski et al., 1996; Fan and Xiao, 1998; Mitchell and Bates, 1998; Walsh et al., 2001). In turn, this will aid in the reduction of conceptual and measurement differences and will further augment the possibility of identifying cultural differences.

The eight consumer decision-making styles consist of subscales or characteristics that define how the consumer makes decisions based on cognitive and personality characteristics Sproles and Kendall (1986). Prior to the development of the Consumer Styles Inventory, no previous inventories were available to researchers and educators Sproles and Kendall (1986). This Styles Inventory was originally tested on secondary home economics students, most of whom were female Sproles and Kendall (1986) and female college students enrolled in the courses offered in the University of Arizona's School of Family and Consumer Resources (Sproles, 1985).

Although the age groups differed, similar results were found between the two groups. The researchers suggested that because these two populations had similar results, the categories of the Consumer Styles Inventory could be reasonably generalized across populations.

Decision-making style refers to a mental orientation which describes the way the consumer makes his choices (Durvasala et al., 1993). Sproles and Kendall (1986, p.276) have defined it in this way "a mental orientation which characterizes a consumer's approach of making choices." since it has cognitive and affective characteristics, it is considered a basic consumer personality (Sproles and Kendall 1986). Others have defined decision-making, in general, as a way to describe individuals and their behaviors (Arroba, 1977).

This definition can be compared to Sproles' (1990) study and suggests that multiple consumer characteristics within decision-making may be correlated to different learning styles. Sproles (1990) further suggested that people may have more than one style of decision-making and it may change depending on the situation.

A consumer decision-making style is also defined as the way a person reacts overall to a purchase decision and it focuses more on the way a decision is made rather than on the actual person making the decision (Arroba, 1977; Thorelli et al., 1975). The actual purchase process is considered as a part of decision-making and is influenced by physiological aspects. 
Consumers process information and interact with their preferred environment and then make a decision based on available alternatives (Bettman, 1979). Deacon and Firebaugh (1975) agreed with Bettmalethat who declared that a consumer should consider alternatives before making a purchase decision. However, Baxter Magolda (1992) implied that the style of decision-making may be influenced by the person's stage of knowing. Sproles and Kendall (1986) identified three categories of consumer decision-making, based on empirical research and literature review. Their research resulted in three proposed categories of characteristics: psychographic/lifestyle, consumer typology, and consumer characteristics. Sproles and Kendall's (1986) literature review described multiple studies that supported their categories of consumer characteristics, and a current review of literature found no additional studies to further broaden the knowledge base of these original, proposed characteristics. Because the Consumer Styles Inventory (CSI) has been tested with multiple cultures with similar results (although some modifications were employed to better describe their population), one can conclude that the CSI is valid. However, to date, no further studies have been conducted with college students in the U.S. Within the realm of consumer-related research, consumer behavior is consistently studied. And although this research has acknowledged that consumers purchase goods and services based on certain decision-making styles, specific studies to evaluate these specific decision-making styles were few prior to the Sproles and Kendall (1986) study.

In fact, Sproles (1985) conducted an exploratory study to develop a conceptual framework for consumer decision-making styles and Sproles and Kendall (1986) then developed the Consumer Styles Inventory. Even Kolb (1981) acknowledged that a person's learning style impacts both their academic and personal lives. Deacon and Firebaugh (1975) proposed a model of decision-making that is considered as the most appropriate method for approaching all decisions, and others have supported this model (Garman, 2002; Goldsmith, 1996; Rice and Tucker, 1986).

Sproles and Kendall (1986) further proposed that consumers approach the marketplace with specific styles of consumer decision-making. Through empirical research, Sproles and Kendall (1986) defined eight categories of decision-making styles: Perfectionistic; Price-Value Consciousness; Brand Consciousness; Novelty-Fashion Consciousness; Confused by Over choice; Recreational Shopping Consciousness; Impulsiveness; Habitual, Brand -Loyal.(Table 2).

\section{Studies Related to the Sproles and Kendall CDMS}

Additional research has confirmed specific categories of the Consumer Styles Inventory. Those studies are described below. 
Table 2. Description of consumer decision-making traits

\begin{tabular}{|c|c|}
\hline Decision-making Traits & Description \\
\hline $\begin{array}{l}\text { Perfectionism or high-quality } \\
\text { consciousness }\end{array}$ & $\begin{array}{l}\text { A characteristic which assesses the degree to which a consumer } \\
\text { searches carefully and systematically for the highest or very best } \\
\text { quality in products. }\end{array}$ \\
\hline Brand consciousness & $\begin{array}{l}\text { Measures a consumer's orientation towards buying the more } \\
\text { expensive and well-known brands in the belief that the higher price of } \\
\text { a product is an indicator of better quality. }\end{array}$ \\
\hline Novelty-fashion consciousness & $\begin{array}{l}\text { A characteristic that identifies consumers who like new and innovative } \\
\text { products and who gain excitement from searching new things. }\end{array}$ \\
\hline Recreational, hedonistic consciousness & $\begin{array}{l}\text { A characteristic which measures the degree to which a consumer finds } \\
\text { shopping a pleasant activity and shops just for the fun of it. }\end{array}$ \\
\hline $\begin{array}{l}\text { Price conscious, and } \\
\text { "value-for-money" shopping } \\
\text { consciousness }\end{array}$ & $\begin{array}{l}\text { A characteristic which identifies the consumers with a high } \\
\text { consciousness of sale prices and lower prices in general. }\end{array}$ \\
\hline Impulsiveness & $\begin{array}{l}\text { A characteristic that identifies the consumers who like to buy without } \\
\text { thinking and who are careless about the amount of money they spend } \\
\text { on buying the best things }\end{array}$ \\
\hline Confused by overchoice & $\begin{array}{l}\text { A characteristic which evaluates those who Know a lot of brands and } \\
\text { stores and know where to buy, and thus they experience an information } \\
\text { overload. }\end{array}$ \\
\hline Habitual, brand-loyal & $\begin{array}{l}\text { A characteristic which indicates consumers with their favorite brands } \\
\text { and stores, and those who like to choose these things repetitively. }\end{array}$ \\
\hline
\end{tabular}

\subsection{Recreational shopping conscious}

For some consumers, shopping is entertaining, without much thought to whether they are getting the best value or best price. These consumers also use shopping as a means of social networking and access to an enjoyable environment (Maynes, 1976).

\subsection{Price-value conscious}

Price is used as criteria for perceived quality of a product according to Jacoby's (1976) review of other research that examines this relationship. Price is also used when other information is unavailable.

\subsection{Habitual, brand-loyal}

Stephenson and Willett's (1969) study of 370 households focused on consumers' shopping styles and how often they shopped at the same retailers. This study investigated store loyalty, shoppers' habits, sensitivity to pricing, and contentment with the shopping experience. 


\section{Studies Using the Consumer Styles Inventory}

Although the original Consumer Styles Inventory (CSI) gleaned similar results using secondary students (Sproles and Kendall, 1986; Sproles, 1985), other studies, mostly with college students, have challenged their findings, based on cultural differences. Results of these studies (Canabal, 2002; Fan and Xiao, 1998) showed similarities in the top consumer decision-making styles, such as Habitual, Brand Conscious.

However, Indian consumers struggled more with Overwhelmed by Overchoice than other populations (Canabal, 2002; Fan and Xiao, 1998; Hafstrom et al., 1992). Further studies were suggested to investigate other international differences, such as macroeconomic conditions (Canabal, 2002) and purchasing power and consumers' maturity in understanding the marketplace (Fan and Xiao 1998; Fan, Xiao, andXu, 1997).

Salleh (2000) analysed consumers' decision-making styles dimensions across different product classes. Wesley, Lehew and Woodside (2006) explored how consumers' decision-making styles relate to their shopping mall behavior and their global evaluations of shopping malls. Cowart and Goldsmith (2007) investigated the influence of consumer decision-making styles on online apparel consumption by college students.

More recently, Kwan, Yeung and $\mathrm{Au}$ (2008) explored the effects of lifestyle characteristics on consumer decision-making styles of young fashion consumers in China. Mokhlis and Salleh(2009) investigated the differing approaches of male and female Malaysian consumers toward shopping and buying activities.

\subsection{China}

Also using college students for their target sample, Fan and Xiao (1998) administered the Sproles and Kendall (1986) Consumer Styles Inventory to see if the consumer decision-making styles were generalizable to Chinese consumers. Based on this study's factor loadings, their findings suggested that the decision-making styles of Impulsive/Careless and Habitual/Brand Loyal were not characteristic of the Chinese sample.

\subsection{Germany}

In Germany, the CSI was administered to adult male and female non-student shoppers, ages 18 and above. Six factors of the original eight included in the CSI were confirmed: Brand Consciousness, Perfectionism, Recreational/Hedonistic, Confused by Overchoice, Impulsiveness, and Novelty-Fashion Consciousness. "Variety seeking was novel to Germany and replaced brand royalty and price-value consciousness factors found in previous countries” (Walsh, Mitchell, andHennig-Thurau, 2001, 73). Table 1 provides an additional comparison of studies that have administered the Consumer Styles Inventory to multiple ethnic samples.

\subsection{Korea}

Hafstrom et al. (1992) found similar factor loadings, to the United States study Sproles and Kendall (1986). However, the Consumer Styles Inventory was modified to include a new 
consumer decision-making style, Time-Energy Conserving. This characteristic included parts of the brand conscious and habitual brand-loyal characteristics of Sproles and Kendall's (1986) original study. The only characteristic not confirmed in the Korean study was novelty fashion conscious.

\subsection{India}

A multi-country study by Lysonski, Srini, and Zotos (1996) questioned the applicability of the CSI to other ethnic samples; however, Cannabal (2002) suggested that the Consumer Styles Inventory had more applicability across cultures. Using college students as the target sample, Canabal (2002) also adapted the conceptual framework to reflect the Germale (Hafstrom et al., 1992) study and factor analysis to determine applicability of the Consumer Styles Inventory. The findings suggested that Indian consumers' impulsiveness was more related to indifference to brands rather than carelessness of decision-making. In fact, this study also added a new category, “dissatisfied/careless,” to reflect this finding.

\subsection{Malaysia}

Kamaruddin and Mokhlis (2003) used social structural variables to determine their influence on consumer decision-making styles. The authors suggested that social class, gender, ethnicity, residence and religion (social structural variables as defined by Kamaruddin and Mokhlis) were related to consumer decision-making. Consumer characteristics were believed to influence decision-making due to their cognitive and affective (attitudinal) components. Adolescents in secondary schools were administered the Consumer Styles Inventory Sproles and Kendall (1986). Using multiple regression analysis, relationships of social structural variables to decision-making styles were tested. Results revealed differences in decision-making styles between males and females. Males tended to be more brand-conscious and females tended to be more recreational shoppers. Adolescents in urban areas tended to be more brand-conscious and novelty-conscious than rural adolescents.

\subsection{Mecadonia}

Using factor analysis, a study conducted by Anic, Sulska, and Razh (2010) with Mecadonia college students produced similar factor loadings to the Sproles and Kendall (1986) study using secondary students in the Mecadonia. Result of this study has identified two homogenous group: recreational consumer and economic consumer. Also significance gender differences were found in four factors of CDMS: brand consciousness, novelty-fashion consciousness, recreational hedonistic consumer and habitual, brand-loyal consumer.

\subsection{United Kingdom}

Using factor analysis, Mitchell and Bates (1998) administered the Consumer Styles Inventory to undergraduate students in the United Kingdom and expanded the categories of consumer decision-making styles from eight Sproles and Kendall (1986) to ten. The two new categories introduced Time-Energy Conserving (Hafstrom et al., 1992) and Store Loyalty. These new categories re-combined some statements from Sproles and Kendall's (1986) other consumer decision-making styles, such as Impulsiveness, Perfectionist, and Brand Loyalty. 


\subsection{Multi-Country}

A study was conducted (Lysonski et al., 1996) with undergraduate business students in four countries to investigate the applicability of the Consumer Styles Inventory in other countries. The countries represented in the sample were the United States, New Zealand, India and Greece. The results of factor analysis were quite similar to Sproles and Kendall (1986). However, this study confirmed seven of the eight Sproles and Kendall decision-making styles, which excluded Price Conscious, Value for Money. This study also suggested decision-making styles from the Consumer Styles Inventory might be influenced by different cultures in other countries, as well as different retail environments (types of retail stores available, whether consumers use credit cards in the particular country). Using varimax rotation of factors, it was determined that the original CSI was more applicable to New Zealand and the United States and was not as applicable to India and Greece. The researchers concluded that there might be specific decision-making style differences within cultures.

Past previous indicated that sproles and kendall (1986) CDMS is more valid for developed countries (Lysonski, 1996). Iran is a vast country with approximately 70 million population where is lack of studying the Iranian CDMS. This study has several purposes: (1) to investigate the applicability of sproles and kendaal (1986) CDMS fro Iranian consumers, (2) identifying specific CDMS for Iranian consumers and, (3) to assess the effects of age, gender, income and marital status of Iranian consumers on their CDMS. (Table3).

Table 3. Comparison of Studies that used the Consumer Styles Inventory

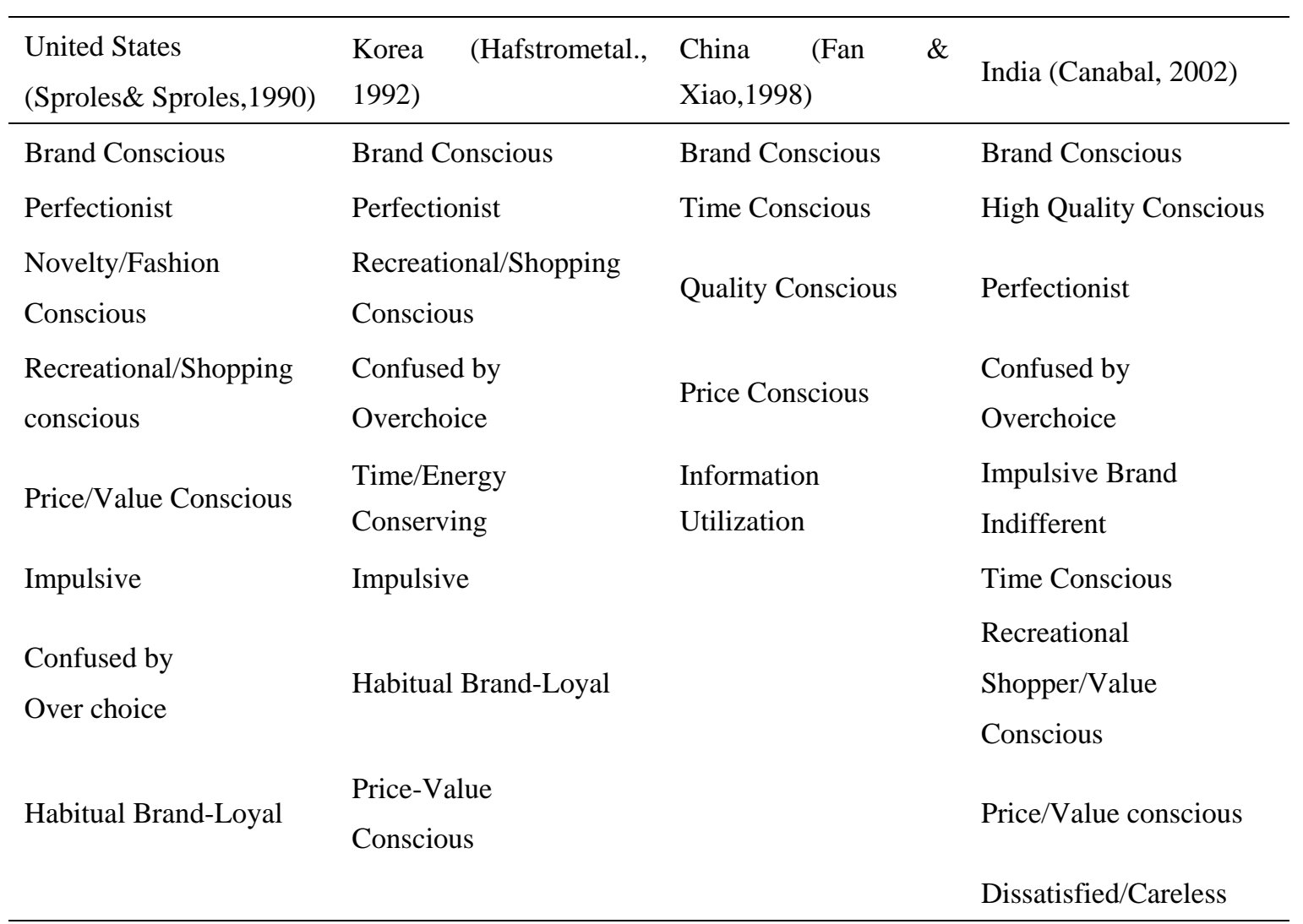


Note: also reflects some different consumer decision-making styles from the Sproles and Kendall (1986) Consumer Styles Inventory. These different styles emerged in some of the individual studies based on cultural differences and were interpretations of the researchers' findings for these studies.

\section{Young-Adult Consumers}

Young-adult consumers provide an interesting topic for the consumer research because they present at least four reasons (Grant and Waite 2003). First, when an adolescent enters early stages of adulthood, they try to establish their own individual personalities and form their behavior patterns, attitudes, and values and thus their own consumption patterns. They buy in order to define themselves and to create an identity of themselves (Holbrook and Schindler 1989). Many of these patterns become fixed ones in individual's lifetimes (Moschis, 1987). Secondly, young people can affect the purchase and decision-making of others (Grant and Waite, 2003). Thirdly, they act as a change agent by influencing society and culture (Leslie, Sparling and Owen, 2001). And finally, from a marketing perspective, young adults are recognized as a specialized market segment which forms a powerful consumer spending group in their own way (Grant and Waite, 2003).

One specific group of young-adult population in Iran that represents the most lucrative market segment is college students. Although the majority of them have no job and just use their educational loans and parents' support, college students represent an extremely large and important market segment for many products and services. They are viewed as a lucrative market since they have higher than average lifetime earnings and are just beginning a major transition period which is a key time to change previous behaviors (Warwick and Mansfield 2000). Marketers like this group because they regard them as potential loyal customers both in the present and in the future (Feldman, 1999).

The role of young people especially in consumer decision making should be defined and examined for several reasons. Young people love to consume and are conscious of their experience (Sproles and Kendall, 1986). Young consumers are recognized as a specialized market segment for a variety of goods and services. The young people often affect family purchasing decisions.

While this segment is a potentially lucrative target for many marketers, it is also complex and must be examined carefully. One aspect of consumer behavior of college students that deserve investigation is their decision-making styles. Nationwide, educators and consumer advocates are concerned about college students' spending habits, easy access to credit cards, credit card debt, and lack financial knowledge (Kidwell and Turrisi, 2000; Norvilitis and Maria, 2002).

Even college administrators are concerned about students' ability to make sound financial decisions (Kidwell and Turrisi, 2000). Some suggestions have been proposed regarding more research on students' consumer decision making (Kidwell and Turrisi, 2000).

Fan and Xiao (1998) inspected the consumer decision-making styles of young Chinese consumers and compared them with the Korean and American consumers. They found that young Chinese consumers share five decision-making styles with their Korean and American 
counterparts, including: brand consciousness, time consciousness, quality consciousness, price consciousness, and information utilization. However, the dimensions of "novelty-fashion consciousness," "impulsiveness," and "habitual-brand-loyal," presented by either or both of the Korean and the American samples, were not discovered among young Chinese consumers. The authors suggested that the dissimilar interpretation of measurements, the different economic development stages, and the divergent market environment are potential factors which contribute to these differences in the consumer decision-making styles.

\section{Methodology}

\subsection{The questionnaire}

A Persian version of the original 40-item CSI Sproles and Kendall (1986) was translated to Persian language and then was back translated (Sekaran, 1983) in order to achieve equivalence of meaning (Malhotra et al., 1996). The questionnaire was then face validated once using exploratory interviews (Malhotra et al., 1996) .The final Persian instrument included original 40 Likert-scale items used by Sproles and Kendall (1986). Respondents were asked to indicate their degree of agreement or disagreement with each item on a 1 base on Likert five-points ( $1=$ strongly disagree; $5=$ strongly agree)

\subsection{The sample}

Most replications of the CSI have used student samples. Previous CSI studies have also used small samples (Hafstrom et al., 1992; Durvasula et al., 1993; Lysonski et al.,1996). 150 convenience samples of students ofShahidBehehsti University were selected. The questionnaires were completed by self-reporting mode. 5 questionnaires were incomplete and excluded from analysis.

\subsection{Statistical methods}

Different statistical techniques were applied. Exploratory principal components analysis using a varimax rotation was used to summarize the items into an underlying set of ICDMS characteristics. All factor loadings of 0.4 or above were identified in the factor matrix, the same level used by Sproles and Kendall (1986). Confirmatory factor analysis was used for measuring applicability and validity of Sproles and Kendall's (1986) for Iranian consumers. Independent sample-test was used for measuring the differences between male/female and single/married consumers in their ICDMS. One way ANOVA was used for measuring the differences among different groups of age and income level in their ICDMS. For estimation of the effect size for independent variables, including gender, marital status, income and age eta squared coefficient ( $\eta 2$ ) (Cohen 1980) has been used. Friedmane analysis of Friedmalefor prioritizing male and female ICDMS was also applied in this regard.

\section{Data Analysis and Results}

Sample profile showed that 73.5 percent are included male and $26.5 \%$ are females. 72.1 percent of respondents are single and the remaining are married. $26.9 \%$ of sample has lower than 300 US dollars monthly income, 53.7\% have monthly income between 300-600 US dollars, $11.9 \%$ have monthly income between $600-900$ US dollars and 7.5\% have monthly 


\section{Macrothink}

Journal of Management Research

ISSN 1941-899X

2012, Vol. 4, No. 2

income above 900 US dollars. $15.3 \%$ of respondents are under 20 old, $48.6 \%$ are between 20-25 years old, 24.3\% are between 26-30 years old, 7.6\% are between 31-35 years old and $4.2 \%$ are above 35 old.

We run CFA procedure for Sproles and kendall (1986) CDMS. Results show the extent that this CDMS is appropriate for Iranian consumers. Results indicate low validity and reliability of using CDMS eight model of Sproles and Kendall (1986) for Iranian consumers. Therefore, the specific shopping styles of Iranian consumers are to be detected. For this purpose, new CDMS EFA was applied. EFA results indicated that there are 12 CDMS for Iranian shoppers. Results of EFA show that only two styles of Sproles and Kendalls are confirmed in Iranian consumers (brand loyalty, habitual and brand conscious). Using EFA by eight factors results in variance extracted equal to $49.75 \%$. Whereas the results of EFA showed that 12-Factor model for Iranian consumers CDMS bring about variance extracted equals to $66.62 \%$.

These findings show that 12-factor model is better fit with Iranian consumers CDMS than Sproles and Kendall eight model of CDMS.

Table 4. presents the exploratory factor analysis for Iranian CDMS. This factor solution explains 66.62 percent of variation (20 percent more than Sproles and Kendall CDMS model). The largest Eigenvalues was 4.83 and the lowest was 1.25. 
Table 4. Iranian Consumer Decision-Making Styles

\begin{tabular}{|c|c|c|c|c|c|}
\hline Factor & Items & $\begin{array}{l}\text { Factor } \\
\text { Loadings }\end{array}$ & Factor & Items & $\begin{array}{l}\text { Factor } \\
\text { Loadings }\end{array}$ \\
\hline & PER3 & .867 & & CON3 & .721 \\
\hline Behavioral & PER2 & .799 & Confused & CON1 & .692 \\
\hline Perfectionistic & PER1 & .775 & $\alpha=0.63$ & CON2 & .691 \\
\hline$\alpha=0.80$ & PER4 & .701 & $\mathrm{VE}=5.31 \%$ & IMP1 & .419 \\
\hline \multicolumn{6}{|l|}{$\mathrm{VE}=7.53 \%$} \\
\hline Brand & BRA3 & .710 & Attitudinal & PER6 & .787 \\
\hline Consciousness & BRA4 & .661 & Perfectionistic & PER5 & -.603 \\
\hline$\alpha=0.76$ & BRA5 & .631 & $\alpha=0.69$ & BRA1 & .449 \\
\hline \multirow[t]{5}{*}{$\mathrm{VE}=7.21 \%$} & & & $\mathrm{VE}=4.89 \%$ & & \\
\hline & BRA2 & .630 & Time-Energy & HED5 & .801 \\
\hline & BRA6 & .622 & Conserving & HED3 & .622 \\
\hline & NOV2 & .848 & $\alpha=0.73$ & PER7 & .584 \\
\hline & & & $\mathrm{VE}=4.70 \%$ & & \\
\hline Fashion & NOV3 & .770 & Hate form & HED1 & .789 \\
\hline Conscious & NOV1 & .676 & Shopping & HED2 & -.607 \\
\hline$\alpha=0.77$ & & & $\alpha=0.68$ & & \\
\hline \multirow[t]{2}{*}{$\mathrm{VE}=7.12 \%$} & & & $\mathrm{VE}=4.66 \%$ & & \\
\hline & IMP4 & .724 & Undemanding & BRA7 & .803 \\
\hline ECONOMIC & IMP3 & .706 & $\alpha=0.66$ & PER8 & .759 \\
\hline$\alpha=0.66$ & & & $\mathrm{VE}=4.53 \%$ & & \\
\hline \multirow[t]{5}{*}{$\mathrm{VE}=5.63 \%$} & IMP2 & -.689 & & HAB4 & .726 \\
\hline & IMP5 & .641 & Variety Seeking & NOV4 & .627 \\
\hline & PRI3 & .521 & $\alpha=0.75$ & NOV5 & 597 \\
\hline & & & $\mathrm{VE}=4.47 \%$ & NOVS & .591 \\
\hline & HAB2 & .855 & & PRI2 & .670 \\
\hline Brand Loyal & HAB1 & .830 & ECO-HEDONIC & PRI1 & .645 \\
\hline$\alpha=0.88$ & HAB3 & .431 & $\alpha=0.71$ & HED4 & .558 \\
\hline $\mathrm{VE}=5.48 \%$ & & & $\mathrm{VE}=5.09 \%$ & & \\
\hline
\end{tabular}

Note. Item CON4 was not assigned to the factors because of low factor loading $(<.4)$

\section{Factor 1: Behavioral Perfectionist}

This factor measures behavioral perfectionist characteristics. This factor items measure consumer actual and behavioral search for the best qualities. Perfectionist can be categorized intotwo sub factor. In behavioral aspect, consumers try actually and make effort and energy for getting the best quality products. In attitudinal aspect, consumers only state their attitudes about getting the best quality goods. Attitudinal perfectionists indicate the beliefs about favorite products. They may do not make any actual effort and behavior for gathering this type of products. Sproles and Kendall (1986) recognized perfectionist style without divide it 
into the attitudinal and behavioral aspects.

Factor 2: Brand Consciousness

As sprloes and kendall (1986) stated, brand Conscious implies positive relationship between price and quality. It measures consumer tendency toward the more expensive and well known brands.

\section{Factor 3: Fashion Conscious}

In Sproles and Kendall's CDMS, they combine novelty seeking and fashion Conscious. Exploratory factor analysis indicated that these two types of CDMS are different and cannot bemerged. Fashionistic consumers tend to adopt the fad and fashions.

Factor 4: Economic

Economic CDMS points out consumers tend to be careful and rational in the shopping time. Economic consumers value for their money the concern for their choices. These types of consumers try to shop the best quality products by cost-benefit analysis.

Factor 5: Brand Loyal

Brand loyal style implies the habitual purchasing. Consumers that have high loyalty tend to repeat their purchase from past brands and stores. Although there is categorization for brand loyalty in to: behavioral and attitudinal but sometimes consumers are loyal to salespeople not brands. They shop the brands that salespeople advised them. Because of high context in Iran culture, loyalty to stores because of its salespeople is apparent.

Factor 6: Confused

Confused consumers are under information overload and cannot decide conveniently. Making decision for shopping is difficult for them. Confusion can be defined "as a result of a temporary extravagance of an individual capacity threshold for absorbing and processing environment stimuli. Consumer Confusion is an emotional state that makes it difficult for consumers to select and interpret stimuli"(Schweize et al., 2006).

\section{Factor 7: Economic-Hedonism}

This factor has two distinct elements. Tendency to hedonic motives from shopping (viewing shopping as a fun) and willingness for shop the cheap product at a lower price. They want to enjoy from the shopping whereas they concern for the price. This style called as Economic-Hedonism (simultaneously be economic and hedonic). They search for lower price product and at the same time tend to enjoy from their shopping experience.

\section{Factor 8: Attitudinal Perfectionist}

As said before, attitudinal perfectionist consumers do not effort to acquire their preferred brand. Despite of desiring best quality brands, any attempts has not been appeared towards this butt. Indeed, they follow a style similar to attitudinal loyalty.

Factor 9: Time-Energy conserving

This type of style means that consumers express concern about their time and energy. They 
spend a little time for shopping. This type of CDMS has been confirmed by three previous studies in South Korea (Hafstrom et al., 1992), the UK (Mitchell and Bates, 1998) and India (Nath, 2009). This style includes two items including: I make my shopping trip fast and shopping the stores wastes my time.

\section{Factor 10: Hate from Shopping}

Two items are included in this style: Shopping is not a pleasant activity to me; going shopping is one of the enjoyable activities of my life (negative). Hating from shopping may be result of many variables such as: type of personality (introversion), market alienation and so on. This factor was not found in previous studies and is a new type of CDMS.

\section{Factor 11: Undemanding}

Neutralists have not high standards for shopping in the other hand; a product doesn't have to be perfect, or the best to satisfy them. This Style is very important for Iranian consumers because unfortunately in Iran business system quality concept is not real priority of producers. Most of Iran manufacturers concern about quality only in theory not in practice. A special case is Iran's car makers. Because of very poor quality of Iranian made cars and poor after sale services, Iranian consumers go below the global standards. They have medium expectations from products they reluctant to extraordinary products.

\section{Factor 12: Variety Seeking}

This style also includes two items: To get variety, I shop different stores and choose different brands; it's fun to buy something new and exciting; I change brands I buy regularly. Variety-seeking is characterized by consumers' tendencies to switch among available Brands Rohem and Rohem (2004). Novelty seekers tend to experience different brands; therefore, they have low brand loyalty. Variety seeking is different with fashion conscious. All of the varied brands that variety seekers adopt are not fashion necessarily.

\section{Demographical Variables and ICDM}

Table5 presents the Gender and Marital effects on ICDMS. Independent samples t-test for comparing decision-making style of male versus female and singles versus married was run. The results showed that female are more fashion conscious than male $(t=1.73 ; \mathrm{p}<.1)$. The remind 11 ICDMSs showed that there are no significant difference between male and woman. eta squared coefficient for fashion conscious equals $2.2 \%$ (small effect based on Cohen's threshold (1980) that implies small effect of gender on fashion conscious Independent samples t-test results for comparing the score of decision-making styles between single and married consumers showed that the score of behavioral perfectionist $(\mathrm{t}=-2.66 ; \mathrm{p}<0.01$ ), brand consciousness $(\mathrm{t}=2.87 ; \mathrm{p}<0.1)$ and fashion conscious $(\mathrm{t}=2.37 ; \mathrm{p}<0.1)$ are different between singles and married individuals. In the other hand, married consumers are more behavioral perfectionist than singles. But singles have more scores in brand consciousness and fashion conscious than married. Eta squared coefficient were estimated for the effect size of marital on behavioral perfectionist (5\%), brand consciousness (5.16\%) and fashion conscious (4\%). Based on Cohen's rule of thumb (Cohen, 1980) the effect of marital on the behavioral 
perfectionist, brand consciousness and fashion conscious are small.

One-way ANOVA results indicated that the age has effects on the behavioral perfectionist $(\mathrm{F}=2.097, \mathrm{p}<0.1)$, brand consciousness $(\mathrm{F}=6.484, \mathrm{p}<0.01)$, fashion conscious $(\mathrm{F}=3.44$, $\mathrm{p}<0.01)$, economic-hedonism $(\mathrm{F}=2.108, \mathrm{p}<0.1)$

Table 5. Gender and Marital effects on ICDMS

\begin{tabular}{|c|c|c|c|c|c|c|}
\hline \multirow{2}{*}{ ICDMS } & \multicolumn{2}{|c|}{ Gender } & & \multicolumn{2}{|l|}{ Marital } & \multirow{2}{*}{$\mathrm{t}$} \\
\hline & Male & Female & & Single & Married & \\
\hline Behavioral Perfectionistic & 4.53 & 4.53 & -.04 & 4.46 & 4.68 & $-2.66^{* * *}$ \\
\hline Brand Consciousness & 2.41 & 2.40 & -.05 & 2.50 & 2.08 & $2.87^{* * *}$ \\
\hline Fashion Conscious & 2.44 & 2.76 & $1.73^{*}$ & 2.64 & 2.27 & $2.37 * *$ \\
\hline Economic & 3.82 & 3.94 & 1.13 & 3.81 & 3.85 & -.36 \\
\hline Brand Loyal & 3.18 & 3.12 & -.29 & 3.19 & 3.19 & -.03 \\
\hline Confused & 3.70 & 3.58 & -.79 & 3.67 & 3.64 & .20 \\
\hline Economic-Hedonism & 2.47 & 2.69 & 1.53 & 2.55 & 2.44 & .71 \\
\hline Attitudinal Perfectionistic & 3.01 & 2.98 & -.24 & 3.00 & 2.98 & .18 \\
\hline Time-Energy conserving & 2.78 & 2.37 & .71 & 2.67 & 2.70 & -.24 \\
\hline Hate form Shopping & 2.93 & 3.02 & -.39 & 2.94 & 2.93 & .07 \\
\hline Undemanding & 3.21 & 3.13 & .91 & 3.29 & 3.00 & 1.56 \\
\hline Variety Seeking & 2.80 & 2.93 & -.04 & 2.88 & 2.72 & 1.20 \\
\hline
\end{tabular}

${ }^{*} \mathrm{p}<.1 ;{ }^{* *} \mathrm{p}<.05 ;{ }^{* * *} \mathrm{p}<.01$

and variety seeking $(\mathrm{F}=4.217, \mathrm{p}<0.01)$. eta square coefficients for five above ICDMS are equal to: behavioral perfectionist ( $\eta 2=5.7 \%$; small effect), brand consciousness $(\eta 2=15.72 \%$; high effect ), fashion conscious ( $\eta 2=9 \%$; moderate effect), economic-hedonism ( $\eta 2=5.7 \%$; small effect) and variety seeking ( $\eta 2=10.8 \%$; moderate effect). 
Table 6. Male versus Female Dominant Styles

\begin{tabular}{lll}
\hline ICDMS & Male* & Female** \\
\hline Behavioral Perfectionistic & 1 & 1 \\
Brand Consciousness & 12 & 11 \\
Fashion Conscious & 10 & 9 \\
Economic & 2 & 2 \\
Brand Loyal & 5 & 4 \\
Confused & 3 & 3 \\
Economic-Hedonism & 11 & 10 \\
Attitudinal Perfectionistic & 6 & 7 \\
Time-Energy conserving & 9 & 12 \\
Hate form Shopping & 7 & 5 \\
Undemanding & 4 & 6 \\
Variety Seeking & 8 & 8 \\
\hline
\end{tabular}

${ }^{*}$ Chi-Square=633.57, $\mathrm{p}<.01$; **Chi-Square=167.38, $\mathrm{p}<.01$;

Post Hoc analysis via LSD procedure employed for detecting that what group makes differences? Analysis revealed that consumers at the age 26-30 old have a high degree for behavioral perfectionist than other consumers except consumers older than 35 old. Results showed that brand consciousness score for different age groups are as below: under 20 year old $>20$-25 year old $>26$-30 year old $>31$-35year old $>$ above 35 year old. Therefore, a negative relationship has been reported between age and brand consciousness score among Iranian consumers. LSD indicated that fashion conscious scores for different groups of age is similar to brand consciousness: under20 old $>20-25$ old $>26-30$ old $>31-35$ old $>$ above 35 old. LSD results showed that the scores of economic-hedonism are as below: under 20 old $>26-30$ old>above 35 old and 20-25 old>26-30 old. So there is an almost negative relationship between age and economic-hedonism style. Results showed that the scores of variety seeking are as below: under 20 old $>26-30$ old; 20-25 old >26-30 old and 31-35 old > above 35 old. Hence we can conclude that there is almost negative relationship between age and variety seeking scores. In the other hand younger Iranian consumers are more variety seeker than older consumers.

Another one-way ANOVA was run for investigating the effect of income level on ICDMS. Results showed that income has effect on: brand conscious ( $F=3.94, p<0.01)$, economic-hedonism ( $\mathrm{F}=2.499, \mathrm{p}<0.1)$, hate from shopping $(\mathrm{F}=2.18, \mathrm{p}<0.1)$ and undemanding $(\mathrm{F}=2.29, \mathrm{p}<0.1)$. eta square coefficients for five above ICDMS are equal to: brand conscious ( $\eta 2=8.3 \%$; moderate effect), economic-hedonism ( $\eta 2=5.45 \%$; small effect ), hate from shopping ( $\eta 2=4.8 \%$; small effect), undemanding ( $\eta 2=5 \%$; small effect). LSD analysis for fashion conscious showed that consumers with 600-900 US dollars monthly income has more score than consumers with under 300 US dollars monthly income. LSD analysis

for economic-hedonism showed that there is positive relationship between 
economic-hedonism score and income level. (consumer with above 900 US dollars monthly income has grater score on fashion conscious style than consumer with 300-600 US dollars monthly income and consumer with under 300 US dollars monthly income). LSD showed that there is positive relationship between hate of shopping score and the consumer income level (600-900 US dollars> 300-600 US dollars> under 300 US dollars).

In the other hand the more consumer income, the more hate of shopping. Analysis also indicated that consumer with 600-900 US dollars monthly income has greater score on undemanding style than consumer with 300-600 US dollars monthly income and consumer with under 300 US dollars monthly income.

Table 7. The effect size of gender, marital status, age and income on ICDMS

\begin{tabular}{|c|c|c|c|c|}
\hline ICDMS & Gender & Marital & Age & Income \\
\hline Behavioral Perfectionistic & -- & $5 \%$ & $5.7 \%$ & -- \\
\hline Brand Consciousness & -- & $5.16 \%$ & $15.7 \%$ & $8.3 \%$ \\
\hline Fashion Conscious & $2.2 \%$ & $4 \%$ & $9 \%$ & -- \\
\hline Economic & -- & -- & -- & -- \\
\hline Brand Loyal & -- & -- & -- & -- \\
\hline Confused & -- & -- & -- & -- \\
\hline Economic-Hedonism & -- & -- & $5.7 \%$ & $5.45 \%$ \\
\hline Attitudinal Perfectionistic & -- & -- & -- & -- \\
\hline Time-Energy conserving & -- & -- & -- & -- \\
\hline Hate form Shopping & -- & -- & -- & $4.8 \%$ \\
\hline Undemanding & -- & -- & -- & $5 \%$ \\
\hline Variety Seeking & -- & -- & $10.8 \%$ & -- \\
\hline
\end{tabular}

\section{Conclusion and Discussion}

Sproles and Kendalls (1986) eight model of CDMS only accounts about $44 \%$ whereas 12 -factor model accounts almost $67 \%$ of data variances. This finding confirmed this claim that that sproles and kendall (1986) CDMS is more valid for developed countries (Lysonski, 1996). Therefore, there is huge need for developing CDMS specific for developing countries. Cox and Dittmar (1995) found that Iranian female consumers are more fashion conscious. Similar to Bakewell and Mitchel (2006), Iranian males still appears as brand conscious as females. T-tests indicated that married consumers are more behavioral perfectionist than single consumers. T-tests results also showed that singles are more brand and fashion conscious than married consumers. Because singles have less expenditure so they have more money for purchasing brand and fashions. Iranian married consumers are very committed to their family (husband/wife and children) and concern the family needs at the first then pay attention to his/her personal interests. Freidman analysis of variance test showed the almost same priorities for 12 ICDMSs except time energy conserving. 
Priority structure of ICDMS showed that time energy conserving has more upper priority in males than females. In the other hand, males tend to shorten the shopping and do shop quickly whereas females consider shopping as interesting activity and fun.

It would be interesting to test this 12-factor model in other developing countries specially the countries that are similar to Iran (in Middle East region). Trying to compare this model among male versus female can also be important and advices. One should be cautious about generalizing the findings as non-probability sampling method was used to derive the sample.

In summary, the general consumer decision-making characteristics of Iranian consumers were classified and some similarities and differences both in the factors and individual item loading found between the Iranian and other countries such as China, Germany, Korea, India, Malaysia, New Zealand and UK.

These distinctions may be because of chance variation, research bias, errors recording coding and analyzing the data, change in the phenomenon over time or more likely that the findings are not generalisable over locations, situation or populations. Nevertheless, an indication of the generalisability of some decision-making characteristics across these countries was found.

A main implication of the finding is that consumer decision-making styles can be used as the basis of segmenting consumers and there appears to be some degree of consistency between the results of essentially quite different studies.

Despite the fact that decision-making traits were able to group consumers into different segments, little consideration has yet been given to whether these segments can be effectively used by marketers, i.e. are they substantial, accessible, actionable, exhaustive, exclusive, responsive and stable? In addition, further research is required to determine how significantly purchase behavior differs at the product and brand level which would give more information on exactly what these segments currently look for in products to satisfy their differing needs.

\section{References}

Albaum, G., \& Peterson R.A. (1984).Empirical Research in International Marketing. Journal of International Business Studies.15.161-173.

Anderson,P. F. (1983).Marketing, Scientific Progress, and Scientific Method. Journal of Marketing.47. 18-31.

Arroba, T. (1977). Styles of Decision-Making and Their Use: An Empirical Study. British Journal of Guidance and Counseling. 5(2). 149-158. http://dx.doi.org/10.1080/0306988770 8258110.

Bakewell, C., \&Mitchell V. W. (2006). Male Versus Female Consumer Decision-Making Style. Journal of Business Research.59. 1297-1300. http://dx.doi.org/10.1016/j.jbusres. 2006.09.008.

Baxter, M. M. (1992). Knowing and reasoning in college. San Francisco: Jossey-Bass.

Bettman, J. R. (1979).An information processing theory of consumer choice. Reading,MA: 
Addison Wesley.

Canabal, J.E. (2002). Decision-Making Styles of Young South Indian Consumers: An Exploratory Study. College Student Journal.36 (1). 12-19.

Cox, J., \& Dittmar H. (1995). The Functions of Clothes and Clothing (dis)satisfaction: A Gender Analysis among British Students. Journal of Consumer Policy. 18. 237-265. http://dx.doi.org/10.1007/BF01016513.

Deacon, R. E., \& Firebaugh, F. M. (1975). Home management context and concepts. Boston: Houghton Mifflin.

Durvasula, S., Lysonski, S., \&Andrews, J. C. (1993). Cross-cultural Generalizability of a Scale for Profiling Consumers' Decision-Making Styles. Journal of Consumer Affairs. 27(1). 55-65. http://dx.doi.org/10.1111/j.1745-6606.1993.tb00737.x

Fan, J. X., \&Xiao, J. J. (1998). Consumer Decision-Making Styles of Young-Adult $\begin{array}{lll}\text { Chinese.Journalof Consumer } & \text { Affairs. }\end{array}$ 275-294. .http://dx.doi.org/10.1111/j.1745-6606.1998.tb00410.x

Fan, J. X., Xiao, J. J., \& Xu, Y. (1997). Decision-Making Styles of Young-Adult Chinese Consumers: An International Comparison. Consumer Interest Annual. 43. 76-81.http://dx.doi.org/10.1111/j.1745-6606.1998.tb00410.x.

Feldman, J. (1999). Back-To-School Buying Guide.Money.28(9). 165-168.

Garman, E. T. (2002). Consumer economic issues in America. Cincinnati: Thomson Learning.

Goldsmith, E. (1996). Resource management for individuals and families. St. Paul, MN: West.

Grant, I. C., \& Waite,K.(2003). Following the Yellow Brick Road-Young Adults' Experiences of the Information Super-Highway. Qualitative Market Research: An International Journal, 6(1). 48-57.

Hafstrom, J. L.,Chae, J. S., \& Chung, Y. S. (1992). Consumer Decision-Making Styles: Comparison between United States and Korean Young Consumers. Journal of Consumer Affairs, 26(1). 146-158. http://dx.doi.org/10.1111/j.1745-6606.1992.tb00020.x

Holbrook, M., \& Schindler, R. M. (1989). Some Explanatory Findings on the Development of Musical Tastes. Journalof Economic, Finance and Administration Science. 16(1). 119-124.

Jacoby, J., \& Chestnut, R. W. (1987). Brand loyalty measurement and management. New York: John Wiley \& Sons.

Kamaruddin, A. R., \& Mokhlis, S. (2003). Consumer Socialization, Social Structural Factors and Decision-Making Styles: A Case Study of Adolescents in Malaysia. International $\begin{array}{lllll}\text { Journal of } & \text { Consumer } & \text { Study. } & \text { 27(2). } & \text { 145-156. }\end{array}$ http://dx.doi.org/10.1046/j.1470-6431.2003.00297.x. 
Kidwell, B., \& Turrisi, R. A.(2000). Cognitive Analysis of Credit Card Acquisitionand College Student Financial Development. Journalof College StudentDevelopment, 41(6). 589-598.

Kolb, D. A. (1981). Learning Styles and Disciplinary Differences. In A. W. Chickering and Associates (Eds.). The Modern American College. 232-255. New York: Prentice-Hall.

Kwan, C. W., Yeung, K. W., \& Au, K. F. (2008). Relationships between Consumer Decision-Making Styles and Lifestyle Characteristics: Young Fashion Consumers in China. $J$ Textile Institute, 99(3). 193-209. http://dx.doi.org/10.1080/00405000701462351

Lee, C., \& Green, R. T. (1991). Cross-Cultural Examination of the FishbeinBehavioral Intentions Model. Journal of International Business Study, 22. 289-305.

Leslie, E., Sparling, P. B., \& Owen,N. (2001). University Campus Settings and the Promotion of Physical Activity in Young Adults: Lessons from Research in Australia and the USA.Health and Education, 101(3). 116-125.

Lysonski, S., Durvasula, S., \& Zotos, Y. (1996). Consumer Decision-Making Styles: A Multi-Country Investigation. European Journalof Marketing, 30(12), 10-21. http://dx.doi.org/10.1108/03090569610153273

Lysonski, S., Srini, D., \& Zotos, Y. (1996). Consumer Decision-Making Styles: A Multi-Country Investigation. European Journalof Marketing, 30(12), 10-21.

Malhotra, N. K., Argawal, J., \& Peterson, M. (1996). Methodological Issues in Cross-Cultural Marketing Research. International Marketing Review, 13(5). 7-43.

Maynes, E. S. (1976). Decision-making for consumers: An introduction to consumer Economics. New York: MacMillan.

Mitchell, V. W., \& Bates, L. (1998). UK Consumer Decision-Making Styles. Journalof Marketing Management, 14. 199-225. http://dx.doi.org/10.1362/026725798784959345.

Moschis, G. P. (1987). Consumer socialization: A life cycle perspective. Lexington. MA: Lexington Books.

Nath,C. K. (2009). Decision-Making Styles in Retail Environment: A New Paradigm. IMA J Man \& Res. 3(4/4).

Norvilitis, J. M., \& Maria, P. S. (2002). Credit Card Debt on College Campuses:Causes, Consequences, and Solutions. College Student Journal.36(3). 356-363.

Rice, A. S., \& Tucker, S. M. (1986). Family life management. New York: MacMillan.

Rohem, H. A., \& Rohem, M. L. (2004). Variety-Seeking and Time of Day: Why Leader Brands Hope Young Adults Shop in the Afternoon, but Follower Brands Hope for Morning. Marketing Letters, 15(4). 213-221.

Salleh, R. (2000). The Analysis of Consumers' Decision-Making Styles Dimensions acrossDifferent Product Classes. Unpublished Doctoral Dissertation, University of 
Strathclyde, Glasgow, UK.

Schweize, M., Kotouc, A. J., \& Wagner, T. (2006). Scale Development for Consumer Confusion. Advances in Consumer Research, 23. 184-190.

Sekaran, U. (1983). Methodological and Theoretical Issues and Advancements in Cross-Cultural Research. Journal of International Business Study. 14(2).61-73.

Sproles, G. B. (1985). From Perfectionism to Faddism: Measuring Consumers' Decision-Making Styles. Paper Presented at the 31stAnnual Conference of the American Council on Consumer Interests, Fort Worth, TX.

Sproles, G. B. (1990). From Perfectionism to Faddism: Measuring Consumer Decision-Making Styles. Proceedings American Council on Consumer Interest Conference Columbia. 79-85.

Sproles, G. B., \& Kendall, E. L. (1986). A Methodology for Profiling Consumers' Decision-Making Styles. Journal of Consumer Affairs, 20(2). 267-279. http://dx.doi.org/10.1111 /j.1745-6606.1986.tb00382.x

Stephenson, P. R., \& Willett, R. (1969). Analysis of Consumers' Retail Patronage Strategies. Paper Presented at the American Marketing Association, Cincinnati, $\mathrm{OH}$.

Walsh, G., Mitchell, V. W., \& Hennig, T. T. (2001). German Consumer Decision-Making $\begin{array}{llll}\text { Styles. Journalof } & \text { Consumer } & \text { Affairs. } & \text { 35(1). }\end{array}$ http://dx.doi.org/10.1111/j.1745-6606.2001.tb00103.x

Warwick, J., \& Mansfield, P. (2000). Credit Card Consumers: College Students'Knowledge and Attitude. Journal of Consumer Marketing, 17(7). 617-626. http://dx.doi.org/10.1108/07363760010357813

Wesley, S., Lehew, W., \&Woodside, A. G.(2006). Consumer Decision-Making Styles and Mall ShoppingBehavior: Building Theory Using Exploratory Data Analysis and the Comparative Method. Journal of Business Research, 59(5). 535-548. http://dx.doi.org/10.1016/j.jbusres.2006.01.005.

Wind, Y. (1987). Issues and Advances in Segmentation Research. Journalof Marketing Research, 15. 317-337. 